\title{
РАСПРЕДЕЛЕНИЕ ДИЛТИАЗЕМА В ОРГАНИЗМЕ ТЕПЛОКРОВНЫХ ЖИВОТНЫХ
}

\author{
(C) Шорманов В.К., Квачахия Л.Л.
}

\author{
Курский государственный медицинский университет, Курск \\ E-mail: Lekso82@yandex.ru
}

\begin{abstract}
Изучены особенности распределения дилтиазема в организме всеядных теплокровных животных (крысы) после внутрижелудочного введения половинной летальной дозы отравляющего вещества. Изолирование дилтиазема из органов, их содержимого и биожидкостей животных проводили ацетоном. Очистку извлеченного соединения осуществляли хроматографией в колонке «Силасорб С-18» 30 мкм (элюент - ацетонитрил - вода $(9,1: 0,9))$. Для идентификации и количественного определения исследуемого соединения использовали методы тонкослойной хроматографии (ТСХ), газовой хроматографии и масс-спектрометрии (ГХ-МС) и УФ-спектрофотометрии. Присутствие наибольших количеств исследуемого вещества зафиксировано в желудке, его содержимом, сердце и печени. Полученные результаты позволяют рекомендовать данные органы в качестве основных объектов судебно-химических экспертиз при отравлении дилтиаземом.
\end{abstract}

Ключевые слова: дилтиазем, распределение в организме, судебно-химический анализ.

\section{DISTRIBUTION OF DILTIAZEM IN THE ORGANISM OF WARMBLOODED ANIMALS}

Shormanov V.K., Kvachakhiya L.L.

Kursk State Medical University, Kursk

The article studies the distribution of Diltiazem in the organism of omnivorous warm-blooded animals (rats) after intragastric introduction of a half-lethal dose of the toxic agent. Isolation of Diltiazem from organs, their contents and bio-fluids of the animals was conducted with the help of acetone. Purification of the extracted compound was carried out by chromatography in a "Silasorb S-18" column 30 micrometers (eluent-ethan nitrile-water (9.1:0.9)). To identify and quantify the tested compound, thin-layer chromatography (TLC), gas chromatography and mass spectrometry (GC-MS), and UV spectrophotometry were used. The presence of the largest quantities of the tested substance is fixed in the stomach, its contents, heart and liver. The results obtained enable us to recommend these organs as the main objects of forensic chemical examination of Diltiazem poisoning.

Keywords: Diltiazem, distribution in the organism, forensic chemical analysis.

Дилтиазем (D-цис-3-Ацетокси-2,3-дигидро-5[2-(диметиламино)этил]-2-(2-метоксифенил)-1,5бензотиазепин-4(5H)-она гидрохлорид) применяется как антагонист ионов кальция при стенокардии, ИБС и гипертонической болезни, а также обладает антиаритмической активностью $[2,5,6]$.

Это белый или не совсем белый кристаллический порошок с горьким вкусом и температурой плавления $213^{\circ} \mathrm{C}$, легко растворимый в воде, метаноле, дихлорметане, плохо растворимый в этаноле $[4,11]$.

Дилтиазем обладает выраженными токсическими свойствами по отношению к теплокровным организмам и может приводить к отравлениям различной степени тяжести. Его $\mathrm{LD}_{50}$ при внутрижелудочном введении лабораторным животным колеблется от $190 \pm 14,61$ мг/кг до $140 \pm$ 14,23 мг/кг $(\mathrm{p}<0,05)$ [6]. Зафиксированы летальные отравления дилтиаземом людей на территории Российской Федерации и за рубежом [1, $4,10,13]$.

Широкое применение дилтиазема в медицинской практике, его токсические свойства, наличие случаев летального отравления делают его важным объектом судебно-химического анализа.
Для изолирования дилтиазема из трупного материала описано использование классических методов, которые не позволяют достичь высокой степени изолирования рассматриваемого вещества (степень извлечения 7-30\%) и относительно малочувствительны $[3,4]$.

Ряд известных вариантов исследования дилтиазема в биологическом (трупном) материале, основанных на изолировании метанолом и ацетонитрилом, не предусматривают достаточно высокой степени очистки, что не позволяет в полной мере использовать возможности современных высокочувствительных методов анализа [3].

Для определения органов и биожидкостей наиболее целесообразных объектов исследования при экспертизе случаев отравления - необходимо предварительное изучение на лабораторных животных особенностей распределения отравляющего вещества в организме теплокровных

Целью настоящей работы явилось изучение характера распределения дилтиазема в организме всеядных теплокровных (крысы) при летальном отравлении, вызванном введением отравляющего агента в желудок. 


\section{МАТЕРИАЛЫ И МЕТОДЫ ИССЛЕДОВАНИЯ}

Объект исследования - субстанция дилтиазема гидрохлорида с содержанием основного вещества не менее 99,9\%, соответствующая НД.

В ходе экспериментов использовались крысы породы Wistar (возраст - 4 месяца, масса - 230245 г), из которых были сформированы 5 опытных групп и 1 контрольная, в каждую из которых входило по 5 особей. Животным опытных групп через пластмассовый зонд вводили рассматриваемое вещество в желудок в виде водной суспензии в количестве 190 мг на 1 кг массы крысы $\left(\mathrm{LD}_{50}\right.$ при пероральном введении). После того как животные погибали, их трупы подвергались вскрытию, одинаковые биологические объекты (органы или биожидкости), взятые от погибших особей внутри каждой из групп, объединяли и исследовали на наличие в них дилтиазема.

Параллельно подобным образом исследовали органы и биожидкости животных контрольной группы.

В качестве аналитических методов рассмотрены тонкослойная хроматография (ТСХ), электронная спектрофотометрия и газовая хроматография и масс-спектрометрия (ГХ-МС), применение которых в анализе дилтиазема известно из литературных источников [9, 12].

Схема изолирования. В каждом случае определенное количество измельченного (средние размеры частиц 0,2-0,4 см) паренхиматозного или полого органа, содержимого полого органа или биожидкости заливали количеством ацетона, в два раза (по массе) превышавшем количество биологического объекта. Смесь биоматериала с изолирующим агентом выдерживали в течение получаса, периодически перемешивая. По истечении указанного времени жидкую часть смеси (ацетоновое извлечение) отделяли от твердого остатка, а процесс настаивания повторяли в описанном выше режиме. Первое и второе ацетоновые извлечения сливали в одну выпарительную чашку, растворитель и остатки воды испаряли в токе воздуха (температурный интервал $18-22^{\circ} \mathrm{C}$ ) до получения сухого остатка $[7,8]$.

Очистка извлеченного соединения. Сухой остаток подвергали обработке 2-3 мл системы растворителей ацетонитрил-вода $(9,1: 0,9)$, получаемый раствор вносили в макроколонку сорбента «Силасорб С-18» 30 мкм (размер колонки $120 \times 11$ мм. Аналит элюировали из колонки двухкомпонентным полярным элюентом ацетонитрилвода $(9,1: 0,9)$. Фракции элюата, истекающего из макроколонки (по 2 мл каждая) собирали в градуированные пробирки. Серию фракций с 8 по 9 сливали в выпарительную чашку, а растворители удаляли из чашки, помещая ее в поток воздуха комнатной температуры. После удаления растворителей остаток обрабатывали 5-7 мл этанола, количественно переносили в мерную колбу вместимостью 10 мл и доводили этанолом до метки (исходный раствор).

В две фарфоровые выпарительные чашки (№ 1 и № 2) вносили по 1,0-4,5 мл исходного раствора и удаляли из него растворитель в потоке воздуха комнатной температуры.

Идентификация в тонком слое сорбента. Остаток, находящийся в чашке № 1, обрабатывали небольшими порциями этанола по 0,2-0,3 мл, количественно перенося раствор в виде полосы на линию старта хроматографической пластины «Сорбфил» ПТСХ-АФ-А-УФ. Рядом на линию старта наносили 5-10 мкл 0,04\% раствора (в этаноле) вещества-свидетеля. Хроматографировали, используя элюент хлороформ-ацетон (5:5). Получаемые тонкослойные хроматограммы проявляли, облучая их УФ светом с длиной волны 254 нм. Дилтиазем идентифицировали по величине Rf.

Идентификация и количественное определение с использованием УФ-спектрофотометрии. Часть хроматограммы с находящимся на ней пятном исследуемого вещества вырезали, вносили в градуированную пробирку вместимостью 10 мл и элюировали вещество из сорбента в течение 15 минут 10 мл этанола в режиме периодического перемешивания. Полученный этанольный элюат отделяли в кварцевую кювету с длиной оптического пути 10 мм и проводили исследование его светопоглощения в диапазоне длин волн от 200 до 360 нм на спектрофотометре модели СФ-2000. Если оптическая плотность элюата превышала 1,4 , его разбавляли этанолом. Количественное определение дилтиазема проводили в области 303 HM.

Идентификация методом газовой хроматографии и масс-спектрометрии (ГX-МС). Сухой остаток, находящийся в выпарительной чашке № 2, обрабатывали 2 мл трихлорметана. 4 мкл, взятые из полученного раствора, вводили в хроматограф фирмы Agilent Technologies (США) модели $6890 \mathrm{~N}$ с масс-селективным квадрупольным детектором модели 5973N (Agilent Technologies). Процесс хроматографирования осуществляли в колонке DB-1MS (J\&WScientific, CША) с неподвижной жидкой фазой диметилполисилоксан (длина колонки 30 м, внутренний диаметр 0,25 мм, толщина пленки фазы 0,25 мкм). Начальная температура термостата колонки составляла $80^{\circ} \mathrm{C}$ (задержка на 2 минуту). Температура программировалась от $80^{\circ} \mathrm{C}$ до $250^{\circ} \mathrm{C}$ со скоростью $40^{\circ} \mathrm{C}$ в минуту с выдержкой при конечной температуре 6 минут. Температура инжектора составляла $280^{\circ} \mathrm{C}$, температура интерфейса - 
$300^{\circ} \mathrm{C}$. В качестве газа-носителя использовался гелий. Подача газа-носителя производилась со скоростью 39 см/с. Проба вводилась в режиме без деления потока, задержка 3 мин. Фрагментация молекул аналита в ионизационной камере осуществлялась с использованием электронного удара (70 эВ). Обнаружение вещества проводилось в режиме регистрации по полному ионному току (диапазон сканирования 40-550 m/z). Анализируемое соединение идентифицировали как по значению времени удерживания, так и по совпадению его масс-спектра с масс-спектром стандарта на $86 \%$ и более.

\section{РЕЗУЛЬТАТЫ ИССЛЕДОВАНИЯ И ИХ ОБСУЖДЕНИЕ}

При идентификации в тонком слое сорбента дилтиазем проявлялся на хроматограммах в УФ свете в виде темных розово-фиолетовых пятен на более светлом общем фоне пластины. Анализируемое вещество идентифицировали на основе совпадения значения его абсолютной хроматографической подвижности (Rf) в тонком слое силикагеля со значением $\mathrm{Rf}$ вещества-стандарта $(0,57 \pm 0,03)$.

По результатам идентификации дилтиазема методом УФ-спектрофотометрии отмечается совпадение формы спектральных кривых аналита, извлеченного из биоматриц, а также положения в них максимумов (при 210, 254 и 278 нм) с этими же характеристиками вещества-стандарта.

Этанольный элюат после идентификации методом УФ-спектрофотометрии упаривали в выпарительной чашке до сухого остатка, остаток

\section{Интенсивность,} усл. ед.

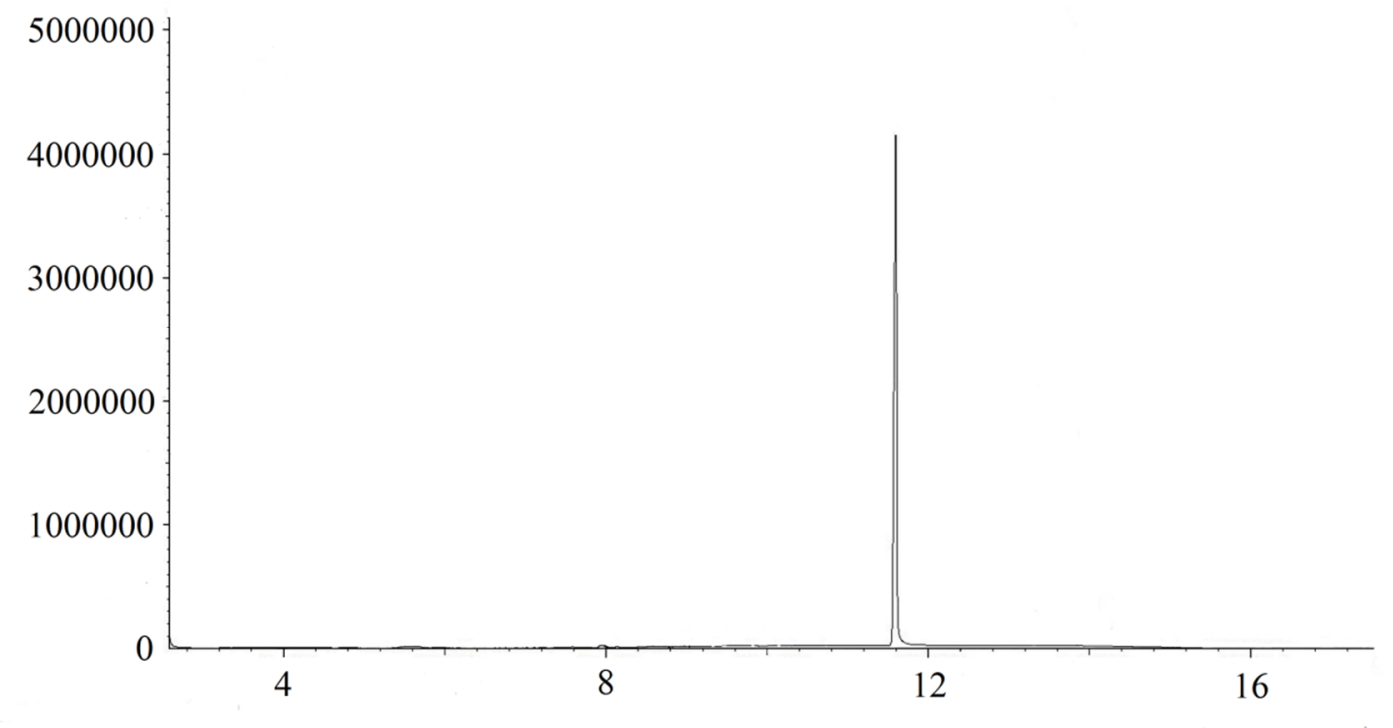

Время удерживания, мин
7,5 мин обрабатывали 0,5 мл 10\% раствора нитрата калия в концентрированной серной кислоте. Реакционную массу разбавляли 1 мл воды, к полученной смеси прибавляли 4,5 мл $20 \%$ раствора гидроксида натрия и измеряли оптическую плотность образующегося окрашенного раствора при 303 нм на фоне раствора, получаемого в контрольном опыте. Количественное содержание дилтиазема определяли, используя уравнение градуировочного графика, и пересчитывали на навеску анализируемого вещества, внесенную в биоматериал.

Относительная ошибка среднего результата при определении дилтиазема данной методикой в субстанции не превышает $1,0 \%$ (при шести параллельных опытах и доверительной вероятности $0,95)$. При исследовании извлечений из биоматриц, взятых от крыс, не получавших дилтиазем, установлено отсутствие данного вещества в паренхиматозных и полых органах, их содержимом, а также в крови животных контрольной серии. Измеренное при длине волн 254 нм фоновое поглощение элюатов из участков хроматограмм, по площади и положению относительно линии старта соответствующих анализируемому веществу, не превышало 0,024 единиц оптической плотности для различных биологических объектов в пересчете на 5 г биоматериала.

Внешний вид газожидкостной хроматограммы вещества-стандарта представлен на рис. 1. Газожидкостные хроматограммы исследуемого аналита, выделенного из некоторых биоматриц (содержимое желудка и печень), изображены соответственно на рис. 2 и рис. 3. 


\section{Интенсивность,}

усл. ед.

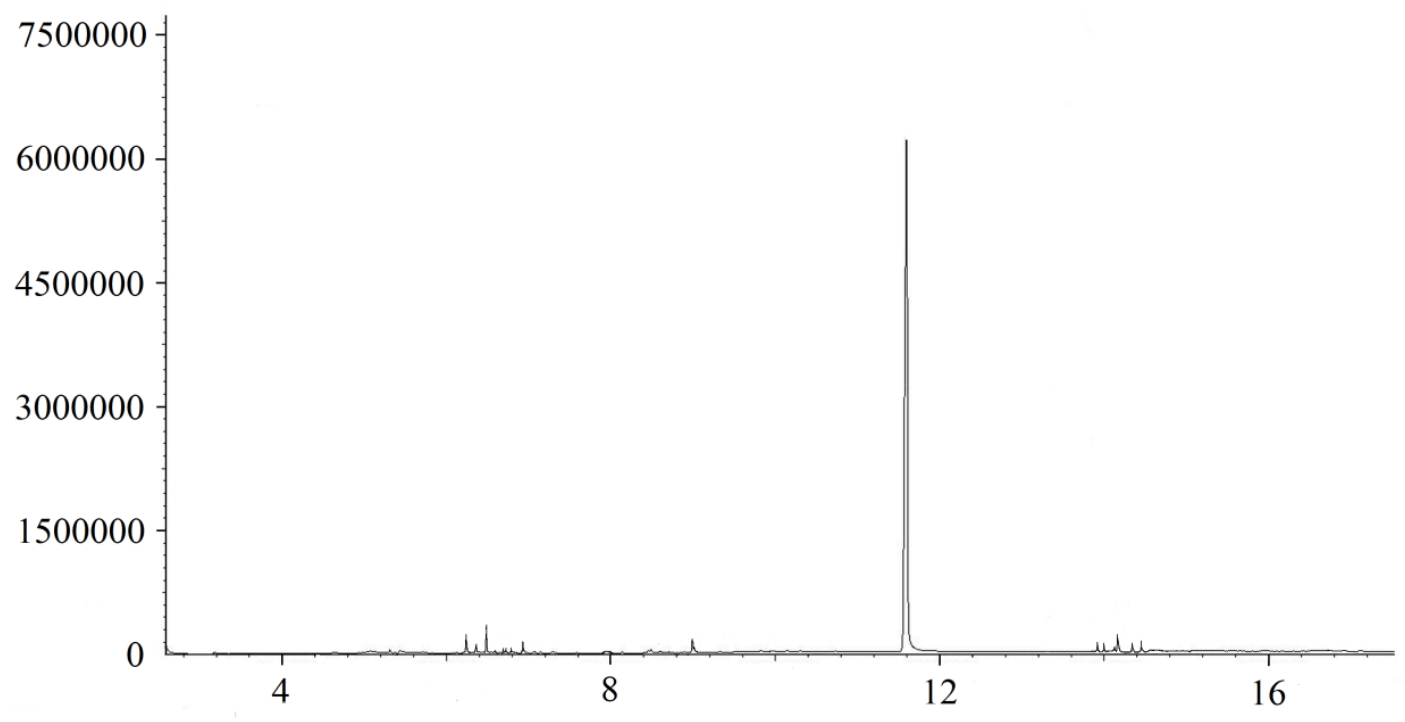

Время удерживания, мин

Рис. 2. Газожидкостная хроматограмма дилтиазема, выделенного из содержимого желудка отравленных животных.

\section{Интенсивность,}

усл. ед.

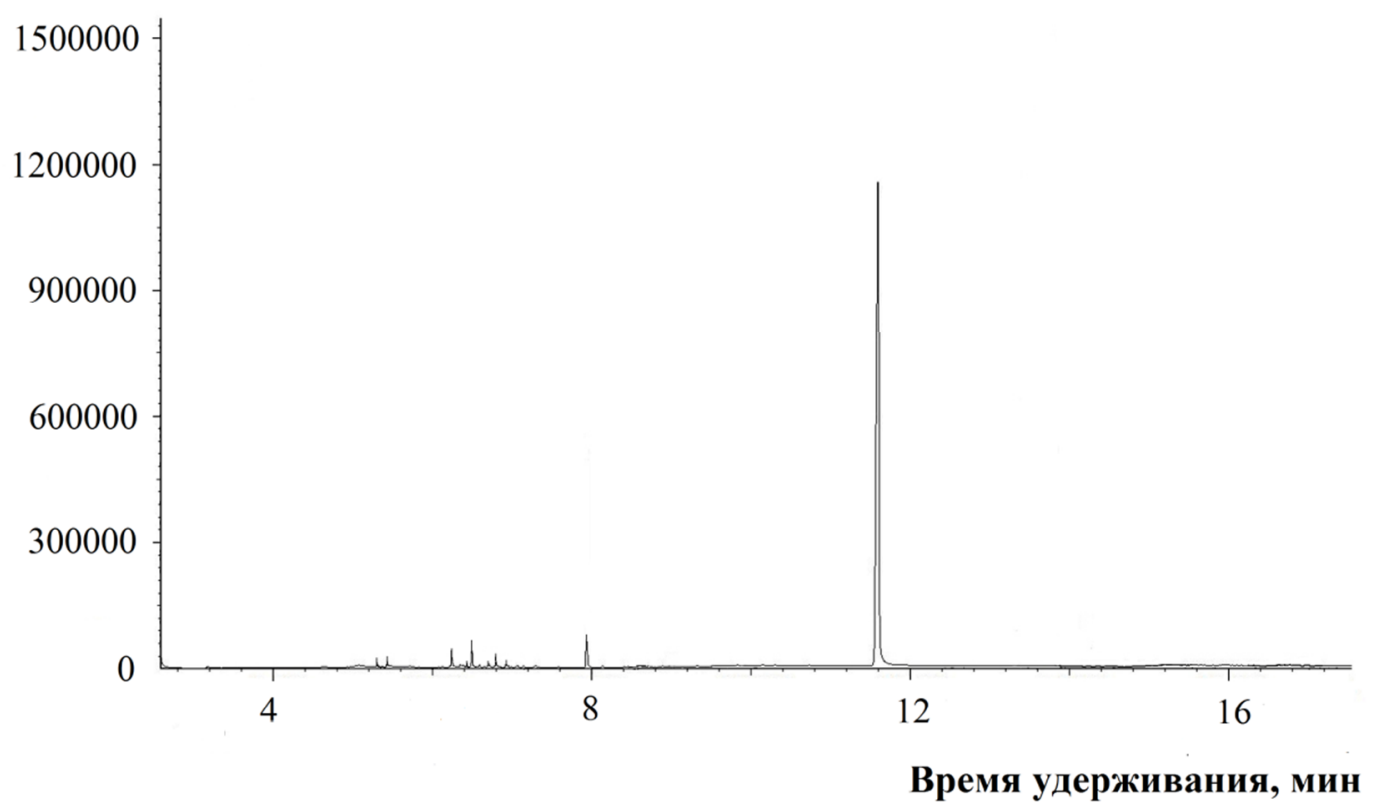

Рис. 3. Газожидкостная хроматограмма дилтиазема, выделеннного из ткани печени.

Таблица 1

Характеристики масс-спектров стандарта дилтиазема и дилтиазема, выделенного из биологических матриц

\begin{tabular}{|c|l|c|}
\hline № & \multicolumn{1}{|c|}{ Анализируемый объект } & $\begin{array}{c}\text { Характеристические осколки молекулы } \\
\text { (положительно заряженные ионы) }\end{array}$ \\
\hline 1. & Стандарт дилтиазема & $41,56,58,71,77,96,103,121,136,150,178$ \\
\hline 2. & Дилтиазем, выделенный из содержимого желудка & $41,55,58,71,77,96,104,121,136,150,178$ \\
\hline 3. & Дилтиазем, выделенный из печени & $41,55,58,71,77,96,104,121,136,150,178$ \\
\hline
\end{tabular}


Таблица 2

Результаты изучения распределения дилтиазема в организме теплокровных (крысы)

\begin{tabular}{|c|c|c|c|c|}
\hline \multirow[b]{2}{*}{$\begin{array}{c}\text { Орган или } \\
\text { биожидкость }\end{array}$} & \multirow{2}{*}{$\begin{array}{c}\text { Масса органов } \\
\text { (суммарная для } 5 \\
\text { особей), взятая для } \\
\text { исследования, г }\end{array}$} & \multicolumn{2}{|c|}{ Найдено дилтиазема } & \multirow[b]{2}{*}{$\begin{array}{c}\text { Метрологические } \\
\text { характеристики }\end{array}$} \\
\hline & & $\begin{array}{c}\text { мг в исследуемой } \\
\text { массе биологического } \\
\text { объекта }\end{array}$ & $\begin{array}{c}\text { мг в } 100 \text { г биологи- } \\
\text { ческого объекта }\end{array}$ & \\
\hline Почки & $\begin{array}{l}6,78 \\
7,13 \\
7,85 \\
7,33 \\
7,49\end{array}$ & $\begin{array}{l}5,434 \\
6,212 \\
6,601 \\
6,621 \\
5,830\end{array}$ & $\begin{array}{l}80,149 \\
87,128 \\
84,083 \\
90,325 \\
77,841\end{array}$ & $\begin{array}{c}\mathrm{x}=83,91 \\
\mathrm{~S}=5,06 \\
\mathrm{~S}_{\mathrm{x}}=2,26 \\
\Delta \mathrm{x}=6,29 \\
\varepsilon=7,50\end{array}$ \\
\hline Печень & $\begin{array}{l}8,33 \\
8,33 \\
8,33 \\
8,33 \\
8,33\end{array}$ & $\begin{array}{l}23,651 \\
26,185 \\
26,755 \\
24,507 \\
25,203\end{array}$ & $\begin{array}{l}283,925 \\
314,343 \\
321,186 \\
294,198 \\
302,557\end{array}$ & $\begin{array}{c}\mathrm{x}=303,24 \\
\mathrm{~S}=15,01 \\
\mathrm{Sx}=6,71 \\
\Delta \mathrm{x}=18,66 \\
\varepsilon=6,15\end{array}$ \\
\hline Сердце & $\begin{array}{l}4,44 \\
4,80 \\
4,29 \\
4,58 \\
4,67 \\
\end{array}$ & $\begin{array}{l}13,060 \\
14,695 \\
13,902 \\
13,200 \\
14,753 \\
\end{array}$ & $\begin{array}{l}294,145 \\
306,138 \\
324,065 \\
288,207 \\
315,916 \\
\end{array}$ & $\begin{array}{c}\mathrm{x}=305,69 \\
\mathrm{~S}=14,84 \\
\mathrm{Sx}=6,64 \\
\Delta \mathrm{x}=18,46 \\
\varepsilon=6,04\end{array}$ \\
\hline Легкие & $\begin{array}{l}8,33 \\
8,33 \\
8,33 \\
8,33 \\
8,33 \\
\end{array}$ & $\begin{array}{l}13,489 \\
11,856 \\
14,020 \\
12,938 \\
12,423 \\
\end{array}$ & $\begin{array}{l}161,931 \\
142,324 \\
168,303 \\
155,314 \\
149,135 \\
\end{array}$ & $\begin{array}{c}\mathrm{x}=155,40 \\
\mathrm{~S}=10,24 \\
\mathrm{Sx}=4,58 \\
\Delta \mathrm{x}=12,73 \\
\varepsilon=8,19\end{array}$ \\
\hline Кровь & $\begin{array}{l}8,33 \\
8,33 \\
8,33 \\
8,33 \\
8,33\end{array}$ & $\begin{array}{l}3,737 \\
4,155 \\
4,033 \\
4,329 \\
3,917 \\
\end{array}$ & $\begin{array}{l}44,859 \\
49,876 \\
48,413 \\
51,971 \\
47,027\end{array}$ & $\begin{array}{c}\mathrm{x}=48,43 \\
\mathrm{~S}=2,71 \\
\mathrm{Sx}=1,21 \\
\Delta \mathrm{x}=3,37 \\
\varepsilon=6,95\end{array}$ \\
\hline $\begin{array}{l}\text { Тонкий } \\
\text { кишечник }\end{array}$ & $\begin{array}{l}8,33 \\
8,33 \\
8,33 \\
8,33 \\
8,33 \\
\end{array}$ & $\begin{array}{l}11,132 \\
11,722 \\
13,066 \\
10,378 \\
12,341 \\
\end{array}$ & $\begin{array}{l}133,632 \\
140,724 \\
156,853 \\
124,591 \\
148,149 \\
\end{array}$ & $\begin{array}{c}\mathrm{x}=140,79 \\
\mathrm{~S}=12,51 \\
\mathrm{Sx}=5,59 \\
\Delta \mathrm{x}=15,55 \\
\varepsilon=11,05\end{array}$ \\
\hline Желудок & $\begin{array}{l}8,33 \\
8,33 \\
8,33 \\
8,33 \\
8,33 \\
\end{array}$ & $\begin{array}{l}94,341 \\
87,015 \\
89,162 \\
91,332 \\
83,983 \\
\end{array}$ & $\begin{array}{l}1132,549 \\
1044,593 \\
1070,370 \\
1096,498 \\
1008,201 \\
\end{array}$ & $\begin{array}{c}\mathrm{x}=1070,44 \\
\mathrm{~S}=47,64 \\
\mathrm{Sx}=21,31 \\
\Delta \mathrm{x}=59,23 \\
\varepsilon=5,53\end{array}$ \\
\hline $\begin{array}{l}\text { Содержимое } \\
\text { желудка }\end{array}$ & $\begin{array}{l}8,33 \\
8,33 \\
8,33 \\
8,33 \\
8,33 \\
\end{array}$ & $\begin{array}{c}114,505 \\
103,403 \\
99,477 \\
92,301 \\
110,415\end{array}$ & $\begin{array}{l}1374,614 \\
1241,333 \\
1194,198 \\
1108,052 \\
1325,511\end{array}$ & $\begin{array}{c}\mathrm{x}=1248,742 \\
\mathrm{~S}=105,547 \\
\mathrm{Sx}=47,202 \\
\Delta \mathrm{x}=131,222 \\
\varepsilon=10,51\end{array}$ \\
\hline Мышцы & $\begin{array}{l}8,33 \\
8,33 \\
8,33 \\
8,33 \\
8,33\end{array}$ & $\begin{array}{l}13,439 \\
13,907 \\
14,991 \\
12,824 \\
14,047\end{array}$ & $\begin{array}{l}161,331 \\
166,950 \\
179,963 \\
153,945 \\
168,629\end{array}$ & $\begin{array}{c}\mathrm{x}=166,164 \\
\mathrm{~S}=9,615 \\
\mathrm{Sx}=4,300 \\
\Delta \mathrm{x}=11,953 \\
\varepsilon=7,19\end{array}$ \\
\hline Селезенка & $\begin{array}{l}3,45 \\
3,33 \\
3,18 \\
3,52 \\
3,24\end{array}$ & $\begin{array}{l}4,396 \\
3,720 \\
3,883 \\
4,665 \\
3,886\end{array}$ & $\begin{array}{l}127,423 \\
111,705 \\
122,106 \\
132,531 \\
119,931\end{array}$ & $\begin{array}{c}\mathrm{x}=122,739 \\
\mathrm{~S}=7,872 \\
\mathrm{Sx}=3,520 \\
\Delta \mathrm{x}=9,787 \\
\varepsilon=7,97\end{array}$ \\
\hline
\end{tabular}


Данные, приводимые на рисунке, позволяют заключить, что в предложенных условиях проведения идентификации сочетанием газожидкостной хроматографии (ГЖХ) и масс-селективного детектирования значение времени удерживания дилтиазема, извлеченного из биоматериала, совпадало с таковым вещества-стандарта и соответствовало интервалу $11,7 \pm 0,14$ минуты.

При сравнении хроматограмм исследуемого соединения $\mathrm{c}$ хроматограммой веществастандарта (метод газовой хроматографии и массспектрометрии) не наблюдалось присутствие дополнительных пиков и заметного смещения базовой линии в зоне, соответствующей промежутку значений времени удерживания 10,6-12,6 мин.

Характеристика масс-спектров веществастандарта, а также дилтиазема, выделенного из биоматриц, представлена в табл. 1.

Как свидетельствуют данные, отраженные в таблице, как в масс-спектре стандарта дилтиазема, так и в масс-спектрах исследуемого вещества, извлеченного из биологических объектов (содержимое желудка и печень), взятых от отравленных животных, отмечается присутствие сигналов характерных осколков (заряженных частиц), наиболее интенсивными из которых являются частицы с массами $(\mathrm{m} / \mathrm{Z}): 58,71$ и 121 . Основным (масса которого принимается за 100\%) является осколок с массой 58.

Результаты определения рассматриваемого соединения в 10 биологических объектах (паренхиматозных органах, полых органах и их содержимом, биожидкостях), взятых от трупов отравленных животных, представлены в табл. 2.

Как видно из таблицы, дилтиазем присутствует в неизменном виде как в органах, так и в крови погибших организмов. Наибольшие количества отравляющего вещества (мг в 100 г органа или биожидкости) обнаруживаются в желудке $(1070,44 \pm 59,23)$ и его содержимом $(1248,74 \pm 131,22)$, сердце $(305,69 \pm 18,46)$ печени $(303,24 \pm 18,66)$ и мышцах $(166,16 \pm 11,95)$, несколько меньшие - в легких $(155,40 \pm 12,73)$, тонком кишечнике с содержимым $(140,79 \pm 15,55)$, селезенке $(122,74 \pm 9,79)$ и крови $(48,43 \pm 3,37)$ отравленных животных.

Проведенные исследования позволяют сделать следующие выводы.

1. Изучено распределение дилтиазема в организме теплокровных животных (крысы) при введении $\mathrm{LD}_{50}$ данного отравляющего вещества в желудок.

2. Показано, что отравляющий агент обнаруживается в значительных количествах в трупах погибших от отравления крыс в неизменном виде.

3. Наибольшие количества дилтиазема присутствуют в желудке $(1070,44 \pm 59,23)$, его содер- жимом $(1248,74 \pm 131,22)$, сердце $(305,69 \pm 18,46)$ и печени $(303,24 \pm 18,66)$.

\section{ЛИТЕРАТУРА}

1. Базы данных «ВЭЖХ-УФ» // Хроматография на благо России / под ред. Курганова А.А. - М. : Граница, 2007. -720 c.

2. Машковский М.Д. Лекарственные средства. 16-е изд., перераб., испр. и доп. - М. : Новая волна, 2012. - $1216 \mathrm{c}$.

3. Медведева Ю.П., Бондарь В.С. Исследование эффективности методов изолирования дилтиазема из биологического материала // Медицинская химия. - 2004. - T. 2, № 6. - С. 97-100.

4. Мингазов А.А., Мусина М.Г., Килин В.В. Изолирование дилтиазема из биоматериала и его идентификация // Актуальные вопросы судебной медицины и права. - 2011. - № 2. - С. 122-125.

5. Романов Б.К. Кальциевая регуляция активности лизосомальных ферментов миокарда // Биомедицинская химия. - 2005. - Т. 51, № 6. - С. 634-642.

6. Усанова А.А., Александровский А.А., Зорькина А.В., Киселева О.М. Влияние эналаприла, дигоксина, атенолола и дилтиазема на перекисное окисление липидов при сочетанных метаболических нарушениях // Рациональная фармакотерапия в кардиологии. - 2009. - № 6. - С. 63-67.

7. Шорманов В.К., Квачахия Л.Л., Ртищев К.П. Определение верапамила в плазме крови // Курский научно-практический вестник «Человек и его здоровье». - 2014. - № 2. - С. 107-113.

8. Шорманов В.К., Квачахия Л.Л., Щербаков Д.П., Чапльггин А.В., Лямин В.Н. Химикотоксикологическое определение дилтиазема // Судебно-медицинская экспертиза. - 2015. - Т. 58, № 2. - C. 39-45. - doi: 10.17116/sudmed 20155823945.

9. Ayad M.M., Abdellatef H.E., Hosny M.M., Sharaf Y.A. Application of 4-chloro-7-nitrobenzofurazan for the analysis of propafenone and diltiazem hydrochlorides using kinetic spectrophotometric and spectrofluorimetric methods // European Journal of Chemistry. 2013. - Vol. 4, N 1. - P. 35-43. - doi: http://dx.doi.org/10.5155/eurjchem.4.1.35-43.713.

10. DeWitt C.R., Waksman J.C. Pharmacology, pathophysiology, and management of calcium channel blocker and beta-blocker toxicity // Toxicol. Rev. - 2004. Vol. 23, N 2. - P. 23-38. - doi: 10.2165/00139709200423040-00003.

11. Clarke's analysis of drugs and poisons in Pharmaceuticals, body fluids and postmortem material. 3rd ed. London : Pharmaceutical Press. - 2004. - Vol. 2. 550 p. - doi: 10.1016/j.tox.2004.06.010.

12. El-Didamony A.M. Indirect spectrophotometric determination of diltiazem hydrochloride in pure form and pharmaceutical formulations // Central European Journal of Chemistry. - 2005. - Vol. 3, N 3. - P. 520536. - doi: 10.2478/BF02479280.

13. Kalin J.R., Wood K.M., Lee A.J. A possible suicide by diltiazem overdose // J. Anal. Toxicol. - 1994. Vol. 18, N 3. $\quad-\quad$ P. 180-182. $\quad-$ doi: 10.1093/jat/18.3.180. 